\title{
Effects of Batrachochytrium dendrobatidis infection on ion concentrations in the boreal toad Anaxyrus (Bufo) boreas boreas
}

\author{
Ryan D. Marcum, Sophie St-Hilaire*, Peter J. Murphy, Kenneth J. Rodnick \\ Department of Biological Sciences, Idaho State University, Pocatello, Idaho 83201, USA
}

\begin{abstract}
Batrachochytrium dendrobatidis causes mortality in various amphibian species including the boreal toad Anaxyrus (Bufo) boreas boreas. The purpose of this study was to determine the physiological effects of this pathogen on experimentally infected boreal toads. Plasma osmolality, sodium, and potassium concentrations were analyzed to evaluate the differences between diseased and non-exposed animals. Infected animals with clinical signs of chytridiomycosis had significantly lower plasma osmolality, sodium, and potassium levels than non-infected animals $(p<0.06)$. On average, clinically infected animals housed in an aquatic environment had sodium and potassium levels of $60.1(\mathrm{SE}=9.7)$ and $2.06(\mathrm{SE}=0.32) \mathrm{mmol}^{-1}$, respectively. These ion levels were significantly lower than the negative controls (sodium $=115.0 \mathrm{mmol} \mathrm{l}^{-1}$, potassium $=3.7 \mathrm{mmol} \mathrm{l}^{-1}$ ) and consistent with the clinical signs observed in affected animals. We propose that infection with $B$. dendrobatidis results in an electrolyte disorder in boreal toads.
\end{abstract}

KEY WORDS: Batrachochytrium dendrobatidis - Boreal toad · Bufo boreas - Osmoregulation . Chytridiomycosis

Resale or republication not permitted without written consent of the publisher

\section{INTRODUCTION}

Batrachochytrium dendrobatidis is an aquatic, fungal pathogen that infects the skin of amphibians (Berger et al. 2005) and has been associated with mortalities and population declines worldwide (Lips 1998, Skerratt et al. 2007). Zoospores infect amphibian keratinocytes and develop into sporangia (Nichols et al. 2001). Clinical signs associated with chytridiomycosis, the disease caused by $B$. dendrobatidis, can include excessive shedding of epidermal cells, lethargy, abnormal posturing, loss of the righting reflex, seizures, and death (Nichols et al. 2001, Carey et al. 2006).

It has been hypothesized that mortality from Batrachochytrium dendrobatidis is caused by damage to the skin, which interferes with osmoregulaton (Berger et al. 2005, Voyles et al. 2007). Voyles et al. $(2007,2009)$ reported decreased blood $\mathrm{pH}$, low plasma osmolality and reduced concentrations of sodium, potassium, chloride, and magnesium in Litoria caerulea, the green tree frog.
Batrachochytrium dendrobatidis has been reported in boreal toads Anaxyrus (Bufo) boreas boreas in the Rocky Mountains of Colorado, Wyoming, and Montana, USA (Muths et al. 2008, Murphy et al. 2009). This species of amphibian resides in a predominantly low humidity woodland habitat above $1800 \mathrm{~m}$, and spends extensive time feeding, basking, and resting in dry microenvironments (Carey 1978). It is unknown whether this pathogen affects osmoregulation in this species of amphibian. The objective of this study was to determine the effects of $B$. dendrobatidis on plasma osmolality, sodium, and potassium concentrations in this species.

\section{MATERIALS AND METHODS}

Fifty-two toads from the Colorado Division of Wildlife Native Aquatic Species Restoration Facility (Alamosa, CO, USA) were housed in individual 5 gallon 
(ca. 18.9 l) glass aquaria. Toad weight ranged from 5 to $33 \mathrm{~g}$ (mean $\pm 1 \mathrm{SE}: 17.9 \mathrm{~g} \pm 1.0$ ). The animals were part of another study to evaluate the role of previous exposure to Batrachochytrium dendrobatidis, temperature, and moisture on the manifestation of chytridiomycosis, the results of which are reported elsewhere. In brief, B. dendrobatidis was grown on TGhL (tryptone, hydrolysed gelatin, lactose) plates at $24^{\circ} \mathrm{C}$ for $48 \mathrm{~h}$. Zoospores were scraped from the plates and placed in TGhL broth. Inoculation of 42 toads was done with $1 \mathrm{ml}$ of $B$. dendrobatidis in TGhL broth at a concentration of $10^{6}$ zoospores $\mathrm{ml}^{-1}$ dripped directly onto the toad for 3 consecutive days. The toads were housed in $700 \mathrm{ml}$ Tupperware with $40 \mathrm{ml}$ of water, which was changed each day during the inoculation period. The isolate used for this study was strain JEL 275 obtained from J. Longcore (Orono, ME, USA). Half of the animals received a second exposure of $B$. dendrobatidis after $64 \mathrm{~d}$. For negative controls, 10 animals were inoculated with sterile TGhL broth. Infection was verified by examination of skin sheds by light microscopy and PCR at time of death. PCR samples were sent to Pisces Molecular for PCR confirmation of $B$. dendrobatidis using the specific PCR assay protocol described in Annis et al. (2004).

Morbidity associated with Batrachochytrium dendrobatidis started 2 wk after the second exposure, with toads showing lethargy, abnormal posturing, and loss of the righting reflex. Half the animals in the study were provided with small platforms to allow them to escape their aquatic environment. The remaining toads were maintained in an aquatic environment. Toads were maintained at room temperature $\left(\sim 15^{\circ} \mathrm{C}\right)$ in 81 aquariums. Tanks were cleaned and toads were fed 2 to 3 crickets every other day. The protocol for this study was approved by the Idaho State University Animal Care Committee.

Moribund animals were euthanized in a $1 \%$ tricaine methanesulfonate (MS-222) bath solution and the spinal cord was severed immediately after death. Blood (45 to $100 \mu \mathrm{l}$ ) from the incision site (posterior to the cranium) was collected in heparinzed capillary tubes (StatSpin Technologies) and spun in a microcentrifuge (CritSpin, IRIS Int.) for 5 min. Plasma was separated from formed elements and stored at $-20^{\circ} \mathrm{C}$ for subsequent analysis. At the end of the experiment (115 d post exposure to Batrachochytrium dendrobatidis), all remaining animals were euthanized, including negative controls, and blood was collected as described above.

Skin samples from the toads' entire abdominal area were taken from exposed and negative control animals at the time of blood collection. The samples were fixed in $10 \%$ buffered formalin. Tissues were processed for histological evaluation by the Oregon State University
Veterinary Diagnostic Laboratory and slides were stained using hematoxylin and eosin. Each sample was assessed for damage to the epidermis.

In total, we collected 37 blood and 27 tissue samples. Not all animals in this study were sampled because 10 died before they could be euthanized. Only animals that were showing signs of disease associated with Batrachochytrium dendrobatidis and negative controls were included in our analyses.

Plasma volumes $<90 \mu$ l were diluted 1:1 with $290 \mathrm{mmol} \mathrm{l}^{-1}$ sodium chloride solution (Wescor). The osmolality of each sample was measured in triplicate using vapor pressure osmometry (Model 5520, Wescor). The average of the 3 measurements was taken and recorded. For samples that were diluted, the following equation was used to determine the actual osmolality:

Plasma osmolality (osmol kg ${ }^{-1}$ ) $=2$ (sample osmolality average $-1 / 2$ dilutant osmolality) Eq. (1)

Plasma samples were assayed for sodium and potassium concentrations by the Portneuf Medical Center (Pocatello, ID, USA) using ion-selective electrodes (Cobas c 501, Roche Diagnostics).

We compared plasma osmolality and ion concentrations between negative controls and clinically infected animals (i.e. showing signs of disease) using an analysis of variance test, and because of our small sample sizes, we also confirmed our results with a KruskalWallis non-parametric test. Due to a loss of plasma samples by the laboratory during processing, we only had sufficient sample sizes to compare ion concentrations for animals housed in aquatic (wet) environments. Nonetheless we graphically presented the data from infected animals housed in a dry environment for illustration purposes. However, we had sufficient data to statistically evaluate whether platforms affected plasma osmolality levels. This was done using a general linear model. All statistical analyses were conducted in Minitab (v 15.1).

\section{RESULTS}

Of the 42 toads infected with Batrachochytrium dendrobatidis, 32 developed chytridiomycosis and were either euthanized or died of the disease. Infection status of all the animals was confirmed throughout the course of the study by microscopic examination of their skin sheds (Fig. 1) and at the end of the study by PCR. All animals with skin sheds positive for $B$. dendrobatidis also tested positive by PCR. Four other exposed toads died due to husbandry issues. These animals were excluded from the analyses as no blood could be collected after death. None of the 10 controls were 


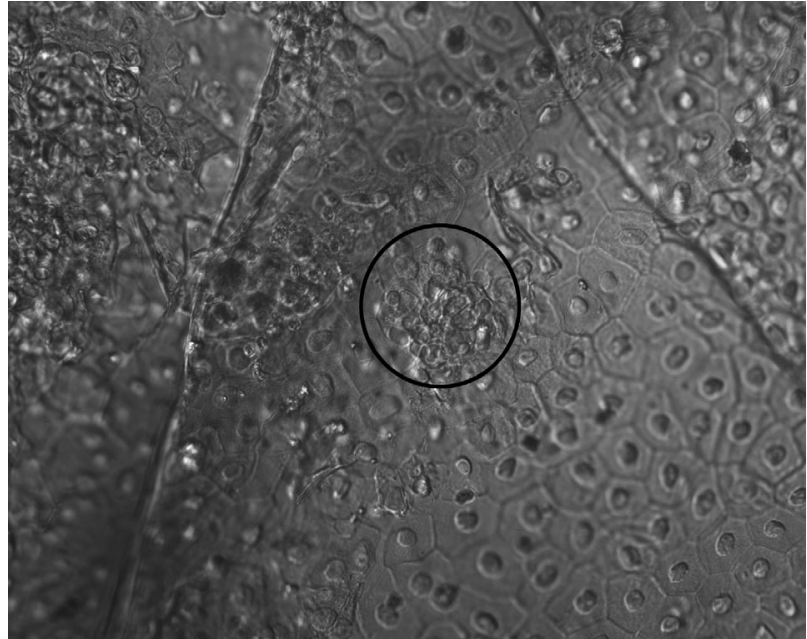

Fig. 1. Batrachochytrium dendrobatidis infecting Anaxyrus (Bufo) boreas boreas. Wet mount of a skin shed from a B. dendrobatidis-infected boreal toad at 400× magnification. Circle: cluster of $B$. dendrobatidis sporangia

infected with $B$. dendrobatidis as determined by examination of shed skin over the course of the study and by PCR.

There was no apparent skin damage in the 10 toads that were not exposed to Batrachochytrium dendrobatidis (Fig. 2a). In contrast, skin damage including sloughing of the epidermis and lymphocytic infiltration was observed by histology in 11 out of the 17 infected toads that were sampled in this study (Fig. 2b) and $B$. dendrobatidis was observed in the skin sheds of all 17 animals sampled (Fig. 1).

Uninfected and infected toads housed in an aquatic environment had an average osmolality of 254 ( $\mathrm{SE}=$ 4.46) and $144\left(\mathrm{SE}=8.35\right.$ ) osmol kg-1 $\mathrm{H}_{2} \mathrm{O}$, respectively. The osmolality was slightly higher for animals housed in a dry environment (Fig. 3a, but providing animals with platforms did not significantly affect the osmolality $(p=0.536)$. Toads held both in an aquatic and a dry environment with severe chytridiomycosis had significantly lower plasma osmolality than their negative counterparts (Kruskal-Wallis ratio, $H_{\text {dry }}=6.82, \mathrm{p}=$ 0.009; $H_{\text {wet }}=9.7, \mathrm{p}=0.002$ )

Animals housed in an aquatic environment and showing severe clinical signs of chytridiomycosis had significantly lower sodium levels than the negative controls $\left(H_{\text {wet }}=7.29, \mathrm{p}=0.007\right)$, with mean levels of $60.1(\mathrm{SE}=9.7)$ and $115.0(\mathrm{SE}=3.5) \mathrm{mmol} \mathrm{l}^{-1}$, respectively (Fig. 3b). This difference was statistically significant using a parameteric test $\left(F_{1,9}=11.17 ; \mathrm{p}=0.009\right)$, but not statistically significant using a non-parametric test $\left(H_{\text {wet }}=3.38, \mathrm{p}=0.06\right)$.

Potassium levels also varied significantly between negative controls and infected toads housed in an
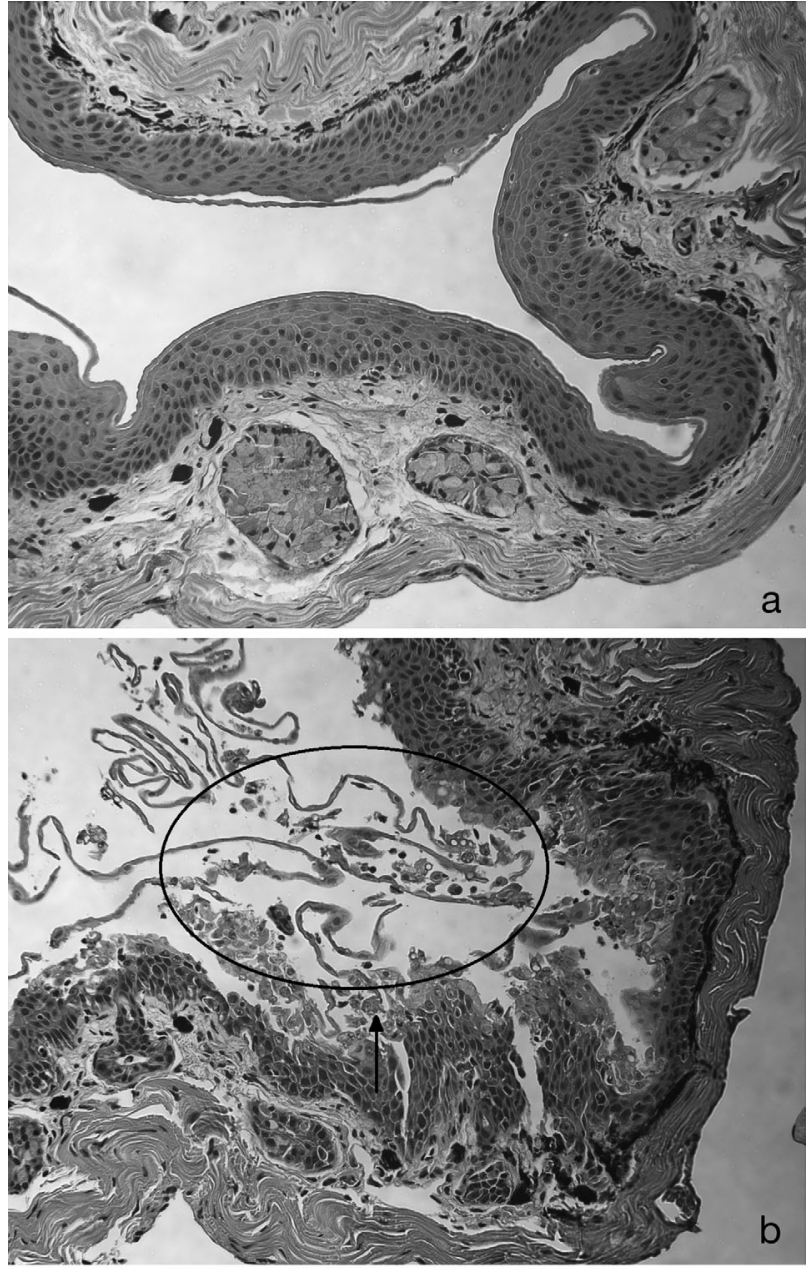

Fig. 2. Batrachochytrium dendrobatidis infecting Anaxyrus (Bufo) boreas boreas. Boreal toad skin from the abdomen of (a) a negative control animal and (b) an infected toad, magnified 200x and hematoxylin and eosin (H\&E) stained. Arrow: example of lymphocytic infiltration (dark cells) and clear vacuoles typical of $B$. dendrobatidis. Circle encompasses epithelial sloughing

aquatic environment $\left(H_{\mathrm{wet}}=4.69, \mathrm{p}=0.03\right.$, $)$. Uninfected and clinically infected toads had potassium concentrations of $3.73(\mathrm{SE}=0.32)$ and $2.06(\mathrm{SE}=0.32)$ mmol $\mathrm{l}^{-1}$, respectively (Fig. 2c).

\section{DISCUSSION}

We detected significant differences in the plasma osmolality, and sodium and potassium ion concentrations in animals clinically infected with Batrachochytrium dendrobatidis and those not exposed to the pathogen (Fig. 3). The levels of sodium and potassium ions measured in clinically infected animals was well below the range reported in Bufo viridis (osmolality $=270 \mathrm{osmol} \mathrm{kg} \mathrm{kg}_{2} \mathrm{O}$, sodium $=113 \mathrm{mmol} \mathrm{l}^{-1}$, potas- 

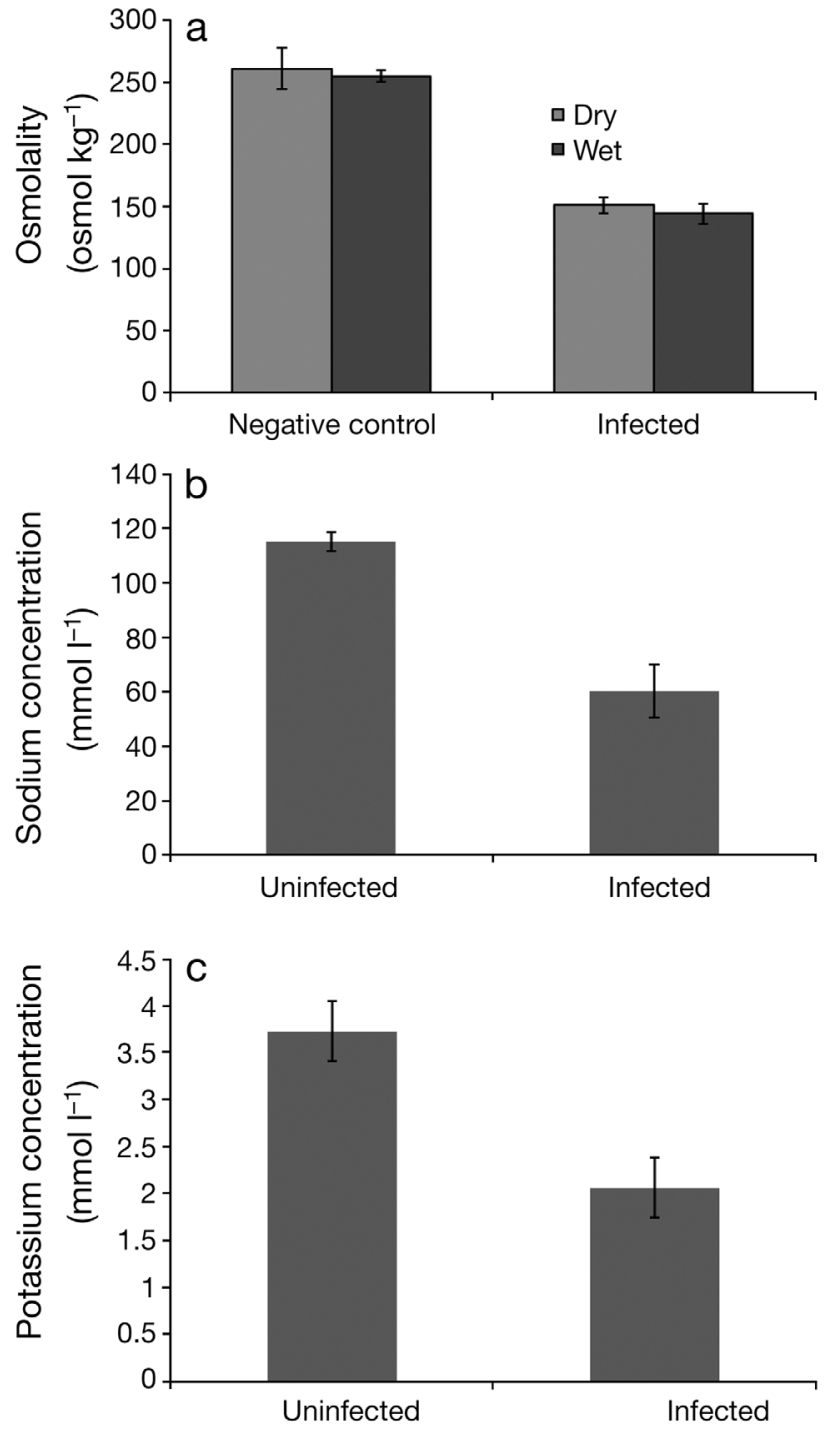

Fig. 3. Batrachochytrium dendrobatidis infecting Anaxyrus (Bufo) boreas boreas. (a) Osmolality for negative control and infected boreal toads housed with (dry) or without (wet) platforms. $(b, c)$ Ion concentrations for negative control and infected toads housed without platforms. Bars: SE of mean

sium $\left.=5 \mathrm{mmol} \mathrm{l}^{-1}\right)($ Shoemaker et al. 1992) and below the levels found in our negative control animals. The results of our study are also consistent with those reported by Voyles et al. $(2007,2009)$ for diseased and normal green tree frogs. They reported slightly lower normal levels for osmolality (217.2 osmol kg-1 $\mathrm{H}_{2} \mathrm{O}$ ), sodium (102.8 $\left.\mathrm{mmol} \mathrm{l}^{-1}\right)$ and potassium (2.74 $\mathrm{mmol} \mathrm{l}^{-1}$ ) than our controls.

The skin plays a critical osmoregulatory role in amphibians and is involved in the active transport of sodium (Boutilier et al.1992). Presumably, damage to the skin could interfere with this process and may contribute to low extracellular sodium concentrations. Further, damaged skin may permit the loss of ions to the environment. Using histology, we observed severe damage to the epidermis in $65 \%$ of the diseased animals, specifically the outer epithelial layer (Fig. 2b). Although not measured in the current study, it is possible that skin damage impaired the active uptake of sodium by the epithelial cells and increased the loss of both sodium and potassium.

Sodium is the most abundant ion in the extracellular fluid and is the main determinant of plasma osmolality. Low sodium imbalance referred to as hyponatremia results in cellular overhydration and can prevent the propagation of action potentials (Eckert et al. 1988) and ultimately limit neuromuscular activity. Hyponatremia is therefore associated with flaccid paralysis and lethargy, both signs observed in toads with chytridiomycosis. Severe hyponatremia can also result in impaired cardiac function and death (Fraser et al. 1991).

Potassium ion deficiency or hypokalemia results in skeletal muscle weakness, reduced muscle tone, and cardiac arrhythmias (Fraser et al. 1991). These signs are once again consistent with those observed in toads with chytridiomycosis. We cannot confirm whether this hypokalemia was due to increased loss of potassium through the skin of boreal toads or possibly increased entry of potassium into cells. The latter has been noted in other animal species after elevated $\beta$-adrenergic activity due to stress (Gardner et al. 1973, Furukawa et al. 1980, Bourne \& Cossins 1982).

The results of low osmolality and plasma sodium and potassium concentrations appear to explain the disease state and mortality associated with Batrachochytrium dendrobatidis in the boreal toad. Specifically, damage caused by $B$. dendrobatidis results in insufficient levels of sodium and potassium in the plasma, possibly due to loss of extracellular sodium and potassium through damaged skin and reduced active uptake of sodium.

Acknowledgements. This project was funded by USGS ParkOriented Biological Support (\#77-NRMS) and by grant UgRCAF08-007 from the Undergraduate Research Grant Committee, Idaho State University, Pocatello, ID.

\section{LITERATURE CITED}

Annis SL, Dastoor FP, Ziel H, Daszak P, Longcore JE (2004) A DNA-based assay identifies Batrachochytrium dendrobatidis infection in the mountain yellow-legged frog (Rana muscosa). J Wildl Dis 44:716-720

Berger L, Hyatt AD, Speare R, Longcore JE (2005) Life cycle stages of the amphibian chytrid Batrachochytrium dendrobatidis. Dis Aquat Org 68:51-63

> Bourne PK, Cossins AR (1982) On the stability of $\mathrm{K}^{+}$influx on erythrocytes of the rainbow trout, Salmo gairdneri, and the role of catecholamine hormones in maintaining in vivo influx activity. J Exp Biol 101:93-104 
Boutilier R, Stiffler D, Toews D (1992) Exchange of water, ions, and respiratory gases in aquatic amphibians. In: Feder M, Burggren W (eds) Environmental physiology of the amphibians. The University of Chicago Press, Chicago, IL

Carey C (1978) Factors affecting body temperatures of toads. Oecologia 2:197-219

Carey C, Bruzgul JE, Livo LJ, Walling ML and others (2006) Experimental exposures of boreal toads (Bufo boreas) to a pathogenic chytrid fungus (Batrachochytrium dendrobatidis). EcoHealth 3:5-21

Eckert R, Randall D, Augustine G (1988) Animal physiology: mechanisms and adaptations, 3rd edn. W.H. Freeman, New York, NY

Fraser C, Bergeron J, Mays A, Aiello S (1991) The merck veterinary manual, 7th edn. Merck \& Co., Rahway, NJ

Furukawa H, Bilezikian JP, Loeb JN (1980) Effects of ouabain and isoproterenol on potassium influx in the turkey erythrocytes. Biochem Biophys Acta 598:345-356

Gardner JD, Klaeveman HL, Bilezikian JP, Aurbach GD (1973) Effects of $\beta$-adrenergic catecholamines on sodium transport in turkey erythrocytes. J Biol Chem 248: 5590-5597

Lips KR (1998) Decline of a tropical mountain amphibian fauna. Conserv Biol 12:106-117

Editorial responsibility: Alex Hyatt, Geelong, Victoria, Australia
Murphy P, St-Hilaire S, Bruer S, Peterson C, Corn PS (2009) Distribution and pathogenicity of Batrachochytrium dendrobatidis in boreal toads from the Grand Teton area of western Wyoming. EcoHealth 6:109-120

Muths E, Pilliod DS, Livo LJ (2008) Distribution and environmental limitations of an amphibian pathogen in the Rocky Mountains, USA. Biol Conserv 141:1484-1492

Nichols DK, Lamirade EW, Pessier AP, Longcore JE (2001) Experimental transmission of cutaneous chytridiomycosis in dendrobatid frogs. J Wildl Dis 37:1-11

Shoemaker VH, Hillman SS, Hillyard SD, Jackson DC, McClanahan LL, Withers PC, Wygoda ML (1992) Exchange of water, ions, and respiratory gases in terrestrial amphibians. In: Feder M, Burggren W (eds) Environmental physiology of the amphibians. The University of Chicago Press, Chicago, IL

Skerratt LF, Berger L, Speare R, Cashins S and others (2007) Spread of chytridiomycosis has caused the rapid global decline and extinction of frogs. EcoHealth 4:125-134

> Voyles J, Berger L, Young S, Speare R and others (2007) Electrolyte depletion and osmotic imbalance in amphibians with chytridiomycosis. Dis Aquat Org 77:113-118

> Voyles J, Young S, Berger L, Campbell C and others (2009) Pathogenesis of chytridiomycosis, a cause of catastrophic amphibian declines. Science 326:582-585

Submitted: August 20, 2009; Accepted: April 27, 2010 Proofs received from author(s): June 9, 2010 